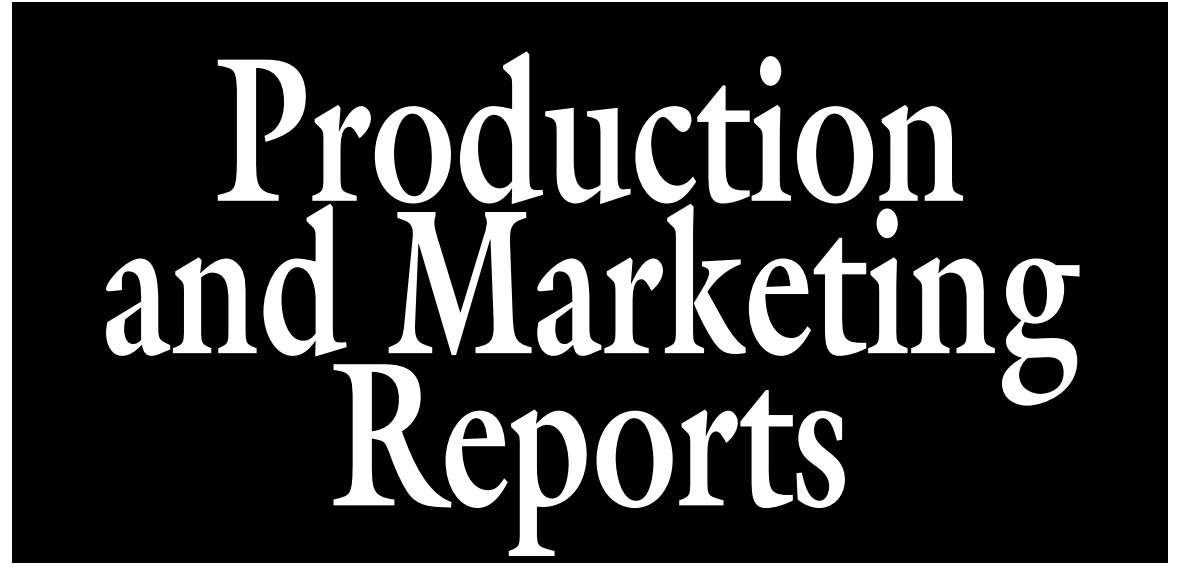

\section{Crop Load Management and the Market Profitability of 'Honeycrisp' Apples}

\author{
R. Karina Gallardo ${ }^{1,5}$, Ines Hanrahan ${ }^{2}$, Yeon A Hong ${ }^{3}$, \\ and James J. Luby ${ }^{4}$
}

AdDitional INDEX wORDs. high-valued apples, size, soluble solids content

SUMMARY. This study assessed the potential impacts on grower profits when the crop load management is not optimal. We used a hedonic pricing model to estimate the relationship between 'Honeycrisp' apple (Malus $\times$ domestica) quantities and prices by size category. This information was used to assess potential changes in grower returns as the grower shifts production toward certain size fruit. A grower would realize a loss of $\$ 5332$ /acre if production of size 48 to 88 count per 40 -lb box decreased by $5 \%$ and size 100 to 163 count/box increased by $5 \%$ compared with current 'Honeycrisp' size distribution. In addition, we used experimental auctions to estimate consumers' willingness-to-pay (WTP) for 'Honeycrisp' quality characteristics. Apple consumers, in this study, were willing to pay an average of $\$ 0.12 / 1 \mathrm{~b}$ more for a one-unit increase in soluble solids concentration. A $\$ 0.12 / 1 b$ discount for a decrease in soluble solids content (SSC) would represent a $\$ 1362$ /acre loss. Optimal sizes and SSC estimated in this study are linked with crop loads no larger than seven fruit $/ \mathrm{cm}^{2}$ trunk cross-sectional area under Washington state growing conditions. Given the increasing popularity of 'Honeycrisp', growers and allied industries should be aware of the importance of preserving the quality of this cultivar to maintain price premiums and thus profit margins.

The University of Minnesota and J. Luby have royalty interests in the 'Honeycrisp' apple cultivar. These relationships have been reviewed and managed by the University of Minnesota in accordance with its conflict of interest policies

${ }^{1}$ Associate Professor, School of Economic Sciences, Puyallup Research and Extension Center, Center for Precision Agriculture and Automated Systems, Washington State University, 2606 W. Pioneer, Puyallup, WA 98371

${ }^{2}$ Project Manager, Washington Tree Fruit Research Commission, 1719 Springwater Avenue, Wenatchee, WA 98801

${ }^{3} \mathrm{PhD}$ Student, School of Economic Sciences, Washington State University, P.O. Box 646210, Hulbert Hall, Pullman, WA 99164

${ }^{4}$ Professor, Department of Horticultural Science, University of Minnesota, Twin Cities, 1970 Folwell Avenue, St. Paul, MN 55108

${ }^{5}$ Corresponding author. E-mail: karina_gallardo@wsu. edu.
' $\mathrm{H}$ oneycrisp' is the sixth largest apple cultivar by acreage in Washington state only after Delicious (known as Red Delicious in the market), Golden Delicious, Gala, Granny Smith, and Fuji [U.S. Department of Agriculture (USDA), 2011]. 'Honeycrisp' is a relatively new cultivar released in 1990 by the University of Minnesota apple-breeding program (U.S. Department of Commerce, 1990). Since the 2000s, this cultivar has increased in popularity in Washington state, from 300 acres in 2001 to 9098 acres in 2011 . As growers seek to diversify cultivar mixes, 'Honeycrisp' has seen market prices higher than other apple cultivars (Schupp et al., 2001). Comparing the average packinghouse free on board (FOB) prices of the six most popular cultivars (in terms of acreage) grown in Washington between 2003 and 2008 , we found that the price per box of 'Honeycrisp' apples is $128 \%$ higher than Fuji and 183\% higher than Delicious (Washington Growers Clearing House Association, 2013) (Table 1).

The market success of 'Honeycrisp' apples stems from their pleasing eating experience. This cultivar demonstrates an exceptionally crisp and juicy texture with a subacid flavor ranging from mild and well balanced to strongly aromatic, depending on the degree of maturity (Luby and Bedford, 1992). Most 'Honeycrisp' consumers value the explosive crispness, juiciness, and flavor delivered. However, these exceptional characteristics are present only when the apple is properly grown, picked at optimum maturity, and stored at adequate conditions (DeEll and Ehsani-Moghaddam, 2010; Robinson and Watkins, 2003; Robinson et al., 2009; Watkins and Nock, 2012).

As the volume of 'Honeycrisp' produced increases, more efforts to maintain optimal quality are required to ensure that it remains one of the most profitable cultivars (Watkins and Nock, 2011). Apple suppliers (e.g., growers, packers, shippers, marketers) must assure that consumers enjoy a consistent and pleasurable eating experience each time they taste fruit of the cultivar. When the eating experience does not meet expectations, consumers

\begin{tabular}{llll}
\hline $\begin{array}{l}\text { Units } \\
\text { To convert U.S. to SI, } \\
\text { multiply by }\end{array}$ & U.S. unit & SI unit & $\begin{array}{l}\text { To convert SI to U.S., } \\
\text { multiply by }\end{array}$ \\
\hline 0.4047 & $\mathrm{acre}(\mathrm{s})$ & $\mathrm{ha}$ & 2.4711 \\
6.4516 & inch & $\mathrm{cm}^{2}$ & 0.1550 \\
0.4536 & $\mathrm{lb}$ & $\mathrm{kg}$ & 2.2046 \\
4.4482 & $\mathrm{lbf}$ & $\mathrm{N}$ & 0.2248 \\
28.3495 & $\mathrm{Oz}$ & $\mathrm{g}$ & 0.0353 \\
7.4892 & $\mathrm{oz} / \mathrm{gal}$ & $\mathrm{g} \cdot \mathrm{L}^{-1}$ & 0.1335 \\
0.0703 & $\mathrm{psi}$ & $\mathrm{kg} \cdot \mathrm{cm}^{-2}$ & 14.2233
\end{tabular}


Table 1. Yearly prices for the six most popular (in terms of acreage) apple cultivars grown in Washington state. ${ }^{\mathrm{z}}$

\begin{tabular}{lcccccc}
\hline & \multicolumn{7}{c}{${\text { Price }(\$ / \text { box })^{\mathrm{y}}}$ Yr } & Honeycrisp & Delicious & Golden Delicious & Granny Smith & Gala & Fuji \\
\hline 2008 & 48.25 & 16.05 & 16.95 & 17.70 & 21.71 & 20.98 \\
2009 & 43.12 & 15.65 & 17.52 & 18.06 & 19.64 & 20.88 \\
2010 & 45.96 & 16.92 & 18.35 & 19.43 & 19.85 & 20.15 \\
2011 & 48.33 & 19.01 & 21.02 & 21.88 & 23.37 & 23.44 \\
2012 & 57.22 & 21.55 & 22.80 & 25.54 & 27.51 & 23.98 \\
2013 & 59.54 & 17.88 & 20.92 & 23.29 & 24.37 & 25.77 \\
Avg & 50.40 & 17.84 & 19.59 & 20.98 & 22.74 & 22.53 \\
\hline
\end{tabular}

${ }^{2}$ Washington Growers Clearing House Association (2013); calculations made by authors.

${ }^{\mathrm{s}} \mathrm{l} / 40-\mathrm{lb}(18.14 \mathrm{~kg})$ box $=\$ 0.055 \mathrm{l} / \mathrm{kg}$.

are less likely to repeat purchases and may switch to other cultivars, other fruit, or other foods. This was observed with U.S. consumers' demand for 'Delicious' in which the decline in perceived eating quality led to decreasing quantities demanded and prices (Quagraine et al., 2003; Winfree and McCluskey, 2005). Nonetheless, 'Delicious' is still the largest (in terms of acreage) cultivar produced in Washington state and, in general, in the United States (U.S. Apple Association, 2014; USDA, 2011). 'Delicious' is targeted to export markets, especially Mexico where this cultivar is popular. Mexico is the largest export market for U.S. apples with $27 \%$ of all U.S. apple exports in 2013 (ProChile, 2011; U.S. Apple Association, 2014).

'Honeycrisp' is not easy to manage, either at the orchard or in postharvest storage. This cultivar is known to have a strong tendency toward biennial bearing, which can result in a large number of small, poor-quality apples in heavy bloom years. Managing flower density and crop load to control the biennial nature of 'Honeycrisp' is one of the greatest challenges for growers (Embree et al., 2007). Crop load also affects the consistent production of fruit of marketable color and size (Wright et al., 2006). Crop loads of around five to six fruit $/ \mathrm{cm}^{2}$ of trunk cross-sectional area (TCA) were found to be optimum to achieve proper fruit color, higher levels of SSC, and medium acidity, even in light bloom years under New York state conditions (Robinson et al., 2009).

Postharvest disorders are also common to 'Honeycrisp'. Soggy breakdown, bitter pit, and soft scald have been identified as principal causes of postharvest fruit losses (DeEll and Ehsani-Moghaddam, 2010; Watkins et al., 2005; Watkins and Nock, 2012). Correct harvest dates and storage temperatures are important to preserve fruit quality during storage (Watkins et al., 2005). Growers should harvest fruit on the basis of background color using spot or selective picking because there is no single maturity index to predict optimum harvest time. In addition, pickers should be extremely cautious to minimize harvest-induced damage such as stem punctures and bruises (Wargo and Watkins, 2004).

Given the susceptibility of the cultivar Honeycrisp to decreases in quality with inadequate pre- and postharvest management, it is unclear how prices and ultimately profitability would be affected if the quality of 'Honeycrisp' decreased. Because a myriad of factors could potentially impact 'Honeycrisp' quality, we focus on two specific consequences of inadequate crop load management: fruit size and SSC (in this study we use SSC as a proxy for sweetness). This article estimates the potential impact on grower profits when the number of fruit per tree is not adequately managed using two different methodologies. First, we use a hedonic pricing model to estimate the relationship between 'Honeycrisp' quantities and prices by size category. This information was used to assess potential changes in grower returns as the grower shifts production toward certain size fruit. Second, we use a second price incentive compatible experimental auction to elicit consumers' WTP for 'Honeycrisp' quality characteristics (e.g., size, absence of defects, firmness, SSC, and tartness). We link WTP results with previous studies on the effects of number of fruit per TCA on SSC to estimate potential losses when not supplying 'Honeycrisp' apples with optimal SSC. We aim to increase awareness in the industry and among horticulturists about the risks of not adequately managing crop load, which could lead to negative effects on the quality of 'Honeycrisp' apples.

\section{Literature reviewed}

One horticultural challenge when cultivating 'Honeycrisp' is the biennial production cycle, which can lead to poor quality due to nonoptimal size, fruit color, SSC, and acidity in years of heavy tree bloom and inadequate yields in light blooming years. Robinson (2008) stated that 'Honeycrisp' could be induced into a biennial cycle by over cropping in the second or third year. However, under New York state growing conditions, biennial bearing could be avoided with proper crop load management consisting of strictly limiting growth to four to six fruit $/ \mathrm{cm}^{2}$ TCA. More specifically, this study shows that four to five fruit/ $\mathrm{cm}^{2}$ TCA would yield a 'Honeycrisp' size of 64 to 72 count per 40 -lb box. Robinson et al. (2009) argued that crop loads of around five to six fruit/ $\mathrm{cm}^{2}$ TCA are optimal with respect to acceptable fruit color, SSC, and acidity, under New York state growing conditions. Hanrahan (I. Hanrahan, unpublished data) conducted a field trial in an eastern Washington commercial orchard block seeking to find a relationship between number of fruit per square centimeter TCA and 'Honeycrisp' quality including size and SSC. She found that under Washington state conditions crop load in the two to four fruit $/ \mathrm{cm}^{2}$ TCA led to highest weight $(270 \mathrm{~g})$ and size (68 count per $40-1 b$ box). Hanrahan (I. Hanrahan, unpublished data) collected data at three orchard locations in eastern Washington with three repetitions at each location seeking to find a relationship between the number of fruit per TCA and 'Honeycrisp' SSC. We attempted to model these data and found that the best fit was a third order polynomial distribution, $\mathrm{SSC}=0.12$ (number of fruit $\left.{ }^{3}\right)-1.97$ (number of fruit $\left.^{2}\right)+9.42$ (number of fruit). The highest SSC corresponded to 3.5 to 7.4 fruit $/ \mathrm{cm}^{2}$ TCA. Other factors besides crop load can influence SSC, including cultivar (Miller et al., 2005), canopy light penetration (Tustin et al., 1988), maturity at harvest (De Castro et al., 2007), mineral nutrition (Fallahi et al., 2008), and postharvest management (Marin et al., 2009). 
Only one study has focused on the effect of fruit sizes on prices and marketing profitability. Schotzko et al. (2001) analyzed the relative profitability of 'D'Anjou' pears (Pyrus $\times$ communis) by fruit size and grade and found that the optimal pear size across different grades is 80 count per $44-1 b$ box. In addition, industry profitability would be increased by $9 \%$ if pears smaller than 120 count per box were culled.

Several studies have analyzed the effect of eating quality (including SSC) on consumer acceptance and WTP for superior apple quality. Manalo (1990) concluded that consumers valued apple crispness the most, followed by size, color, and flavor. DaillantSpinnler et al. (1996) found that British consumers considered apple texture and taste to be more important than aroma and appearance. Kajikawa (1998) reported that Japanese wholesale prices for apples imported from New Zealand and the United States were associated with SSC, acidity, and juice content. Jesionkowska et al. (2006) determined that Polish consumers valued flavor and juiciness the most, followed by SSC and firmness. McCluskey et al. (2007) found that a premium of $\$ 0.26 / \mathrm{lb}$ could be attained if apples had a firmness of at least $14 \mathrm{lbf}$ and SSC of at least $13.50 \%$. Dinis et al. (2011) emphasized the importance of apple taste, appearance, smell, and origin to consumers' valuation of apples. McCluskey et al. (2013) found that consumers in the Pacific northwestern United States were willing to pay more for firmness in 'Delicious' than in 'Gala' $(\$ 0.58 / \mathrm{lb}$ vs. $\$ 0.04 / \mathrm{lb})$, but were willing to pay more for SSC in 'Gala' compared with 'Delicious' ( $\$ 0.40 / \%$ SSC vs. $\$ 0.37 / \%$ SSC). This study will add to the literature by estimating the effects of 'Honeycrisp' size and SSC on prices and industry profitability.

Experimental auctions are a popular marketing research methodology to elicit WTP for a diversity of goods and attributes (Lusk and Shogren, 2007). Experimental auctions have been applied to study a wide range of agricultural and food products, including consumers' preferences for attributes in horticultural plants (Yue et al., 2012, 2010), fresh produce (Yue and Tong, 2009), genetically modified food (Colson et al., 2011; Huffman et al., 2003; Volinsky et al.,
2009), and food attributes in general (Corrigan and Rousu, 2008; Feuz et al., 2004; Lee et al., 2011; Nalley et al., 2006; Wayua et al., 2009). In this study, we use a second price incentive compatible auction along with a sensory taste test to elicit individuals' preferences for 'Honeycrisp' appearance and eating-quality attributes.

\section{Methodology}

HEDONIC PRICING MODEL FOR 'HoneyCrisP' APPLES. To calculate the effect of 'Honeycrisp' fruit size on prices received by growers, we followed the methodology developed by Schotzko et al. (2001), who used a model of price determination in which pear characteristics were mixed with other factors affecting pear demand. They hypothesized that pear prices were a function of size and grade as well as consumer demand for competing fruit, season, crop year conditions, and the volumes of pears supplied.

Apple prices are based on the USDA standards for grades that include external characteristics such as size, ripeness, color, shape, and freedom from defects, among others (USDA, 2002). We modeled 'Honeycrisp' apple grower prices as a function of external characteristics such as size and limited the analysis to only one grade, Washington extra fancy, which was the only grade for which price and shipping volume data were available for each size.

Monthly 'Honeycrisp' FOB prices (prices at the packinghouse door) per size and production volumes (in terms of weekly warehouse shipments) were collected from the Washington Clearing House Association for Sept. 2010 to July 2013. Monthly production volumes for 'Gala' and 'Delicious' apples as well as pear prices were collected from the same source. We collected monthly apple import statistics from the USDA (2014). Since data for monthly U.S. apple production outside of Washington state were unavailable, we used the total U.S. quantities of apples in storage as a proxy. This information is available in the U.S. Apple Association (2014) monthly apple-holding reports.

To analyze the data, we used a two-stage least square (2SLS) model using Proc Syslin in SAS (version 9.3; SAS Institute, Cary, NC). Because the effect of quantities on market prices is not necessarily immediate, we used 1-month lags for the quantities produced of 'Honeycrisp', 'Gala', and 'Delicious' . Because the relationship between apple size and prices is not linear, we included size in its third-order polynomial form to capture the curvature. The empirical specification used follows:

$$
\begin{aligned}
\operatorname{ln~HCprice~}_{i, j}= & \alpha_{0}+\alpha_{1} \text { HCquantity }_{i-1, j} \\
& +\alpha_{2} \text { Galaquantity }_{i-1, j} \\
& +\alpha_{3} \text { RDquantity }_{i-1, j} \\
& +\alpha_{4} \text { appleimports }_{i} \\
& +\alpha_{5} \text { applestorage }_{i} \\
& +\alpha_{6} \text { pear price }_{i}+\alpha_{7} \text { size }_{j} \\
& +\alpha_{8} \operatorname{size}_{j}^{2}+\alpha_{9} \text { size }_{j}^{3} \\
& +\sum_{m=\text { Jan }_{10} \text { month }_{m, i}}^{\text {Dec }} \alpha_{10} \\
& +\sum_{r=2010}^{2013} \alpha_{11} \text { year }_{r}+e_{i}
\end{aligned}
$$

where $\ln \mathrm{HCprice}_{i, j}$ is the logarithm of the 'Honeycrisp' FOB grower price for month $i$ and size $j$; HCquantity $_{i-1, j}$ is the quantity produced of 'Honeycrisp' size $j$ in month $i$-1; Galaquantity ${ }_{i-1, j}$ is the quantity produced of 'Gala' size $j$ in month $i$-1; RDquantity ${ }_{i-1, j}$ is the quantity produced of 'Delicious' size $j$ in month $i$ - 1 ; appleimports ${ }_{i}$ is the quantity of apples imported in month $i$; applestorage $e_{i}$ is the quantity of apples in stock or holdings in states other than Washington in month $i$; pear price $_{i}$ is the price for U.S.produced fresh pears in month $i$; size $_{j}, \operatorname{size}_{j}^{2}$, and $\operatorname{size}_{j}^{3}$ are the first-, second-, and third-order terms for $j$ apple sizes (sizes considered were $48,56,64,72,80,88,100,113,125$, $138,150,163$ count per 40-lb box); month $_{m, i}$ is the vector of indicator variables for month to capture seasonality effects ( $m=$ January, ..., December); year $_{r}$ is the vector of indicator variables for year to capture year effects $(r=2010$, $\ldots, 2013) ; \alpha_{0}$ is the intercept term capturing all effects not included in this model; $\alpha_{1}-\alpha_{9}$ are the marginal values for all variables included in the model; and $e_{i}$ is the error term, which follows a standard normal distribution.

Parameters were estimated using Proc Syslin in SAS (version 9.3). Data observations were standardized to the means. To avoid perfect multicollinearity due to inclusion of redundant information, the binary variables of 
the month July and year 2010 were omitted for estimation purposes only. Thus, July serves as the reference for the interpretation of the estimated coefficients of the rest of binary variables for January,..., December; and 2010 serves the same purpose for years $2011, \ldots, 2013$.

In relation to the estimated effect of sizes on 'Honeycrisp' prices, we replace the range of sizes used in this study $(48, \ldots, 163$ count/box $)$ in the following expression:

$$
\begin{aligned}
\ln \text { HCprice }_{i, j}= & \alpha_{7} \operatorname{size}_{j}+\alpha_{8} \operatorname{size}_{j}^{2} \\
& +\alpha_{9} \operatorname{size}_{j}^{3}
\end{aligned}
$$

which is a portion of Eq. [1] and can be depicted as $h_{j}(j)$. Then we estimate the relative effects with respect to size 48 count/box, which is the largest apple size in our data of the following equation:

$$
h_{j}^{*}(j)=\frac{h_{j}^{(J)}}{h_{j}^{(48)}}
$$

where $b_{i}^{*}(J)$ is the relative effect of size $j, h_{j}^{(J)}$ is the function of prices with respect to each apple size as depicted in Eq. [2], and $h_{j}^{(48)}$ is the function of prices with respect to apple size 48 count/box, as depicted in Eq. [2].

To investigate the effect of 'Honeycrisp' quantities shipped on our prices, we estimate the price flexibility with the following equation (Schotzko et al., 2001):

$$
\begin{aligned}
& \text { Price flexibility }_{j} \\
& =\frac{\% \Delta \text { HCprice }_{j}}{\% \Delta \text { HCquantity }_{j}} \\
& =\alpha_{1} \times \text { HCquantity }_{j} \times 100
\end{aligned}
$$

where Price flexibility ${ }_{j}$ is the price flexibility for size $j, \alpha_{1}$ is the marginal value of quantity from Eq. [1], and HCquantity $_{j}$ is the quantities of 'Honeycrisp' shipped for each size $j$. To estimate the price change due to an increase in quantity, the following calculation was used:

$$
\begin{aligned}
\text { HCprice }_{j}^{1}= & \text { HCprice }_{j}^{0}+\left(\text { Price flexibility }_{j}\right. \\
& \left.\times \text { HCprice }_{j}^{0}\right)
\end{aligned}
$$

where HCprice ${ }_{j}^{1}$ is 'Honeycrisp' price level 1 after quantities shipped have increased and HCprice ${ }_{j}^{0}$ is the price level 0 before quantities shipped increased.

EXPERIMENTAL AUCTIONS WITH 'Honeycrisp' apples. To estimate the effects of SSC on 'Honeycrisp' profitability, a sensory taste test and experimental auctions with 'Honeycrisp' apples were conducted during Fall 2012 in three U.S. locations: Pullman, WA; St. Paul, MN; and Portland, OR. There were 128 apple consumer participants in each location, divided into eight sessions with 16 individuals per session. Three rounds of bids with 'Honeycrisp' apples were conducted in each session. To ensure a random distribution of apples with different attributes across participants, two orthogonal designs were created. One considered two levels of size (large and small) and two levels of defect coverage (no defects and defects) for the first round of bids. The second design considered two levels of firmness (lower and higher than $12 \mathrm{lbf}$ ) and two levels of SSC (lower and higher than 13\% SSC). 'Honeycrisp' harvested at different times from different growing locations within eastern Washington and stored in different conditions were procured so that variability in SSC and firmness could be ensured.

Recall that we used a second price auction with three rounds of bids. During the first round, two apple samples were displayed at the front of the room and participants were asked to visually inspect them. Next, participants submitted their bids for each of the two samples observed (BIDl). The highest and second highest bids for each sample were posted on a board in the front of the room. During the second round, each participant was given a sliced and peeled apple sample, each with a different combination of eating-quality attributes (firmness, SSC, and tartness). Portions of each sample were sent to the laboratory to obtain quantitative measures of firmness in pounds per square inch, SSC (percent), and tartness expressed in grams per liter malic acid. Next, they submitted the second round of bids (BID2) for each of the two samples based on the eating-quality information. As in the first round, the highest and second highest bids for both samples were posted on the board in the front of the room.
During the third round (BID3), participants were informed that the apples they had tasted corresponded to the apples that they had visually inspected in the first round. They were asked to submit the third round of bids for both samples, taking into consideration the overall information provided, including external appearance and eating quality. Then, the highest and second highest bids for the third round were posted. Because there were three different auction rounds (and only one round could be used to identify the auction winner), a binding auction round was chosen randomly. Finally, the participants completed a questionnaire about their demographic information and consumption habits. This study focused on the third round of bids because it included external and internal quality characteristics.

Auction data were analyzed using a type of hedonic price model in which price was a function of the quality characteristics: fruit size, external defects, firmness, SSC, and tartness. Binary variables for location (where the study was conducted) were included:

$$
\begin{aligned}
\operatorname{Bid}_{k}= & \beta_{0}+\beta_{1} \text { size }_{k}+\beta_{2} \text { defects }_{k} \\
& +\beta_{3} \text { firmness }_{k}+\beta_{4} \text { firmness }_{k} \\
& +\beta_{5} \text { SSC }_{k}+\beta_{6} \text { SSC }_{k}+\beta_{7} \text { tartness }_{k} \\
& +\beta_{8} \text { tartness }_{k}+\beta_{9} \text { Portland } \\
& +\beta_{10} \text { St.Paul }+\mu_{k}
\end{aligned}
$$

where $\mathrm{Bid}_{k}$ is the bid for 'Honeycrisp' apple sample $k$; $\operatorname{size}_{k}$ is the binary variable for size, with 0 representing a size less than 3 inches in diameter and 1 representing a size more than 3 inches in diameter; defects $_{k}$ is a binary variable for the presence of external defects, with 0 representing absence and 1 otherwise; firmness ${ }_{k}$ is the instrumental measure for firmness in psi; firmness $2_{k}$ is firmness in its quadratic form; $\mathrm{SSC}_{k}$ is the instrumental measure for $\mathrm{SSC}_{\mathrm{SSC}} \mathrm{SS}_{k}$ is SC in its quadratic form; tartness $s_{k}$ is the instrumental measure for acid content expressed in grams per liter malic acid; tartness $2_{k}$ is tartness in its quadratic form; Portland and St. Paul are binary variables to control for location (to avoid multicollinearity, the 
Table 2. Parameter estimates for the two stage least square model depicting 'Honeycrisp' apples the effect of various factors on prices received by growers.

\begin{tabular}{|c|c|}
\hline Variable & Parameter estimate (SE) \\
\hline Intercept & $\begin{array}{l}-7.078 * * * \\
(0.841)\end{array}$ \\
\hline Quantity produced 'Honeycrisp' apples (1-mo. lag) & $\begin{array}{l}-1.70 \times 10^{-7 * * *} \\
\left(4.73 \times 10^{-8}\right)\end{array}$ \\
\hline Quantity produced 'Gala' apples (1-mo. lag) & $\begin{array}{l}4.68 \times 10^{-11 \mathrm{NS}} \\
\left(1.08 \times 10^{-8}\right)\end{array}$ \\
\hline Quantity produced 'Delicious' apples (1-mo. lag) & $\begin{array}{l}9.87 \times 10^{-9 \mathrm{NS}} \\
\left(5.57 \times 10^{-9}\right)\end{array}$ \\
\hline Quantity apple imported & $\begin{array}{l}1.19 \times 10^{-6 * * *} \\
\left(2.07 \times 10^{-7}\right)\end{array}$ \\
\hline Quantity of apples stored not in Washington & $\begin{array}{l}-3.11 \times 10^{-16 *} \\
\left(1.07 \times 10^{-16}\right)\end{array}$ \\
\hline Price pears & $\begin{array}{r}-0.887^{*} \\
(0.353)\end{array}$ \\
\hline 'Honeycrisp' size & $\begin{array}{l}0.070 * * * \\
(0.013)\end{array}$ \\
\hline 'Honeycrisp' apples size $\times$ size & $\begin{array}{l}-0.001 * * * \\
\left(1.28 \times 10^{-4}\right)\end{array}$ \\
\hline 'Honeycrisp' apples size $\times$ size $\times$ size & $\begin{array}{l}2.04 \times 10^{-6 * * *} \\
\left(3.99 \times 10^{-7}\right)\end{array}$ \\
\hline January & $\begin{array}{l}3.870 * * * \\
(0.486)\end{array}$ \\
\hline February & $\begin{array}{l}3.839 * * * \\
(0.481)\end{array}$ \\
\hline March & $\begin{array}{l}3.387 * * * \\
(0.425)\end{array}$ \\
\hline April & $\begin{array}{l}2.859 * * * \\
(0.356)\end{array}$ \\
\hline May & $\begin{array}{l}1.252^{* * *} \\
(0.256)\end{array}$ \\
\hline June & $\begin{array}{l}-0.117^{\mathrm{NS}} \\
(0.208)\end{array}$ \\
\hline August & $\begin{array}{l}1.379 * * * \\
(0.211)\end{array}$ \\
\hline September & $\begin{array}{l}3.481^{* * *} \\
(0.460)\end{array}$ \\
\hline October & $\begin{array}{l}3.617 * * * \\
(0.482)\end{array}$ \\
\hline November & $\begin{array}{l}4.055^{* * *} \\
(0.485)\end{array}$ \\
\hline December & $\begin{array}{l}4.015 * * * \\
(0.482)\end{array}$ \\
\hline 2011 & $\begin{array}{l}-0.049^{\mathrm{NS}} \\
(0045)\end{array}$ \\
\hline 2012 & $\begin{array}{l}0.233^{* * *} \\
(0.047)\end{array}$ \\
\hline 2013 & $\begin{array}{l}0.420 * * * \\
(0.070)\end{array}$ \\
\hline $\begin{array}{l}\text { Observations (no.) } \\
\text { Adjusted } R^{2}\end{array}$ & $\begin{array}{l}293 \\
0.791\end{array}$ \\
\hline
\end{tabular}

NS, ${ }^{* * *},{ }^{* \star *}$ Nonsignificant or significant at $P \leq 0.05,0.01$, or 0.001 , respectively.

binary variable category for Pullman was omitted); $\beta_{0}$ is the parameter intercept; $\beta_{1}-\beta_{8}$ are the marginal values for each quality attribute; $\beta_{9}$ and $\beta_{10}$ are the parameters for location; and $\mu_{k}$ is the error term, which follows a normal distribution.
Coefficient estimates for Eq. [6] were estimated using Proc Reg in SAS (version 9.3).

\section{Results and discussion}

HEDONIC PRICING MODEL FOR 'HONEYCRISP' APPLES. The parameter estimates for Eq. [1] are presented in Table 2 . The 1 -month lag of quantity shipped of 'Honeycrisp' had a negative effect on 'Honeycrisp' grower prices (Table 2). This means, for example that an increase of 50,000 $40-1 \mathrm{~b}$ boxes in the marketplace would decrease prices of 'Honeycrisp' by $0.85 \%$. In Table 4 , we report the 'Honeycrisp' quantities in pounds shipped during the period of study, for each fruit size (count per box), the percentage that each size represents relative to the total volume of fruit shipped, and the average FOB price corresponding to each size. To estimate how an increase in quantities shipped will affect each size, we assume that the increase would happen in the same proportions as reported in Table 4. Then, using Eq. [5], we estimate the price levels for each size when quantities shipped increased (Fig. 2).

Increases in quantities produced would mostly affect sizes in the 64 to 72 count/box. Quantities of apples imported had a positive effect on 'Honeycrisp' prices, signaling that imported apples behave as substitutes to 'Honeycrisp'. The United States mostly imports apples from Chile and New Zealand during the off-season months (March through August) (Huang, 2013). The most popular apple cultivar produced in these countries is 'Gala' (USDA, 2014).

Fruit size had a nonlinear effect on 'Honeycrisp' grower prices, meaning that the highest prices can be achieved over a range of sizes. Estimated relative effects of sizes on 'Honeycrisp' prices are plotted in Fig. 1. Estimated prices for each size is plotted against the cost of producing 'Honeycrisp' in Fig. 2. In both figures, all other variables constant, sizes of 64 to 72 count/box exhibit the highest predicted prices $(\$ 49.2$ to $\$ 48.6$ per box). One can observe in Fig. 3 an inflection point in size 100 count/box. Thus, we simulated what would be the likely losses per acre if current 'Honeycrisp' size distribution changes. Table 4 illustrates 'Honeycrisp' quantities in pounds for each size for the period of study. We estimated a weighted average price for the initial size distribution at $\$ 43 /$ box. Next, we calculated different weighted average prices by changing the distribution of sizes (e.g., by decreasing the proportion of size 48 to 88 count/box by $5 \%$ and 
Table 3. Parameter estimates for the model depicting apple consumers' willingness to pay for 'Honeycrisp' apples appearance and eating quality characteristics.

\begin{tabular}{lc}
\hline Variable $^{\mathrm{z}}$ & ${\text { Parameter estimate }(\mathrm{SE})^{\mathrm{z}}}^{-}$ \\
\hline Dependent variable & $\operatorname{Bid}(\$ / \mathrm{lb})$ \\
Intercept & $-5.226^{\mathrm{NS}}(4.112)$ \\
Binary variable for size & $0.143^{\mathrm{NS}}(0.091)$ \\
Binary variable for defects & $-0.247^{* *}(0.089)$ \\
Firmness (psi) & $0.035^{\mathrm{NS}}(0.170)$ \\
Firmness $\times$ firmness (psi) & $0.0003^{\mathrm{NS}}(0.006)$ \\
Soluble solids content [SSC (\%)] & $1.388^{*}(0.736)$ \\
SSC $\times$ SSC $(\%)$ & $-0.052^{*}(0.030)$ \\
Tartness $\left(\mathrm{g} \cdot \mathrm{L}^{-1}\right.$ malic acid) & $-1.843^{* * *}(0.551)$ \\
Tartness ${ }^{2}\left(\mathrm{~g} \cdot \mathrm{L}^{-1}\right.$ malic acid) & $0.263^{* * *}(0.078)$ \\
Binary variable for location St. Paul, MN & $1.218^{* * *}(0.114)$ \\
Binary variable for location Portland, OR & $0.254^{*}(0.112)$ \\
Observations (no.) & 378 \\
Adjusted $R^{2}$ & 0.306 \\
\hline
\end{tabular}

${ }^{2} \$ 1 / \mathrm{lb}=\$ 2.2046 / \mathrm{kg}, \mathrm{l} \mathrm{psi}=0.0703 \mathrm{~kg} \cdot \mathrm{cm}^{-2}, \mathrm{lg} \cdot \mathrm{L}^{-1}=0.1335 \mathrm{oz} / \mathrm{gal}$.

NS, ${ }^{*}, * *, * *$ Nonsignificant or significant at $P \leq 0.05,0.01$, or 0.001 , respectively.

Table 4. Quantities of 'Honeycrisp' apples shipped and average free on board (FOB) grower prices for each size category. ${ }^{\mathrm{z}}$

\begin{tabular}{lccc}
\hline $\begin{array}{l}\text { Size } \\
(\text { count/box })^{\mathbf{y}}\end{array}$ & $\begin{array}{c}\text { 'Honeycrisp' apples } \\
\text { quantity (lb) }\end{array}$ & $\begin{array}{c}\text { Quantities shipped in } \\
\text { each size category (\%) }\end{array}$ & $\begin{array}{c}\text { Avg FOB price for each } \\
\text { size count }(\mathbf{S} / \mathbf{b o x})^{\mathbf{y}}\end{array}$ \\
\hline 48 & 571,400 & 18 & 40.96 \\
56 & 423,300 & 13 & 46.71 \\
64 & 393,500 & 12 & 49.16 \\
72 & 438,100 & 14 & 48.64 \\
80 & 371,200 & 12 & 45.34 \\
88 & 369,100 & 12 & 44.05 \\
100 & 274,200 & 9 & 34.70 \\
113 & 168,000 & 5 & 34.70 \\
125 & 79,200 & 2 & 26.68 \\
138 & 55,200 & 2 & 21.61 \\
150 & 19,000 & 1 & 19.33 \\
163 & 20,000 & 1 & 17.72 \\
Weighted avg price $(\$ / 825-1 b \text { bin })^{y}$ & & 42.55 \\
\hline
\end{tabular}

${ }^{2}$ Washington Growers Clearing House Association (2013); calculations made by authors.

y $1 \mathrm{lb}=0.4536 \mathrm{~kg}, \$ 1 / 40-\mathrm{lb}(18.14 \mathrm{~kg})$ box $=\$ 0.0551 / \mathrm{kg}, \$ 1 / 825-\mathrm{lb}(374.21 \mathrm{~kg}) \mathrm{bin}=\$ 2.6723 / \mathrm{Mg}$

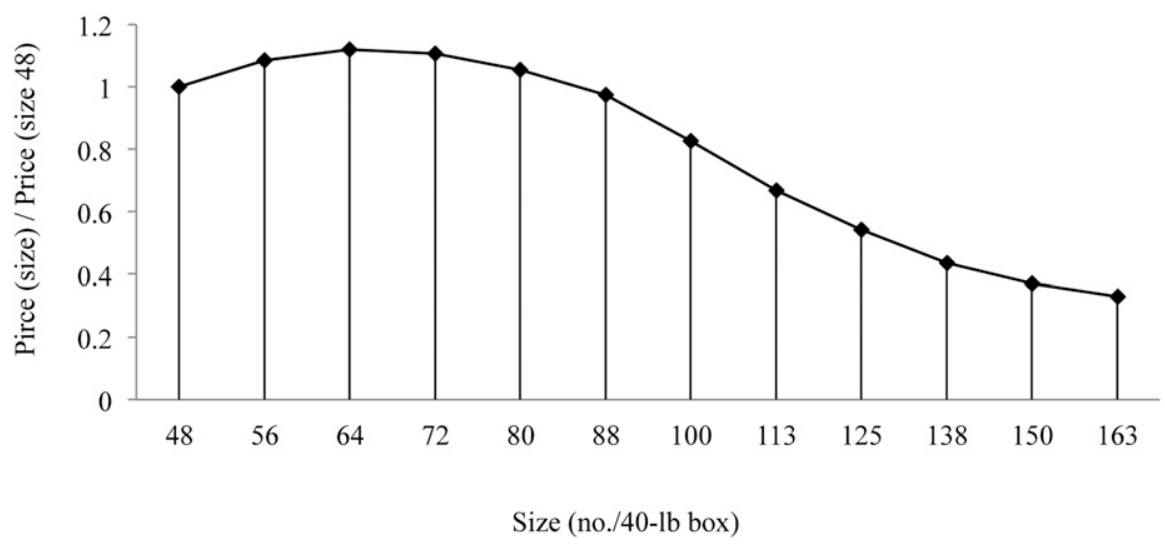

Fig. 1. Relative effects of 'Honeycrisp' apple sizes on prices received by growers in dollars per 40-1b (18.14 kg) box; $\$ 1 / 40-1 b$ box $=\$ 0.0551 / \mathrm{kg}$. increasing the proportion of size 100 to 163 count/box by $5 \%$ ). Using the calculator of net returns per acre at various prices and yields of 'Honeycrisp' in Galinato and Gallardo (2012), we estimated the different net returns per acre at different weighted average prices (Table 5). A grower would realize a loss of $\$ 5332 /$ acre if production of size 48 to 88 count/box decreased by $5 \%$ and size 100 to 163 count/box increased by $5 \%$ compared with current 'Honeycrisp' size distribution. If one considers the data published by Robinson (2008) in New York state, the crop load four to five fruit $/ \mathrm{cm}^{2}$ TCA associated with sizes 64 to 72 count/ box-would be expected to yield the highest predicted prices of $\$ 49.2$ to $\$ 48.6$ per box. Hanrahan (I. Hanrahan, unpublished data) found that crop load two to four fruit $/ \mathrm{cm}^{2}$ TCA in Washington state could yield fruit size 68 count/box with a predicted price of $\$ 48 /$ box.

During the period of study, 'Honeycrisp' prices were the highest in November, December, January, and February. 'Honeycrisp' harvest in Washington state typically happens September through early October. Sophisticated storage technology [CA, and the use of 1-methylcyclopropene (MCP)] has proven to be effective in extending the marketing season for most apples (in a range of 2-7 months), leading to fresh apples exhibiting fairly weak seasonal grower price patterns (Plattner et al., 2014). Such technology has not yet been proven successful with 'Honeycrisp' in most growing areas, given its susceptibility to develop disorders during storage (Watkins et al., 2005). Nonetheless, packinghouses in Washington state have managed to extend storage periods for 'Honeycrisp' (Good Fruit Grower, 2014). 'Honeycrisp' prices received by growers in 2013 and 2012 were higher than prices in 2010. This was in part due to the major frost and cold weather event in the Spring of 2012 that severely reduced the crop in eastern (decline by $31 \%$ ) and midwestern (decline by $79 \%$ ) states (U.S. Apple Association, 2014).

EXPERIMENTAL AUCTIONS WITH 'HoneyCrisp' apples. Parameter estimates for Eq. [6] are presented in Table 3. We observe that apple consumers were expecting a discount of 


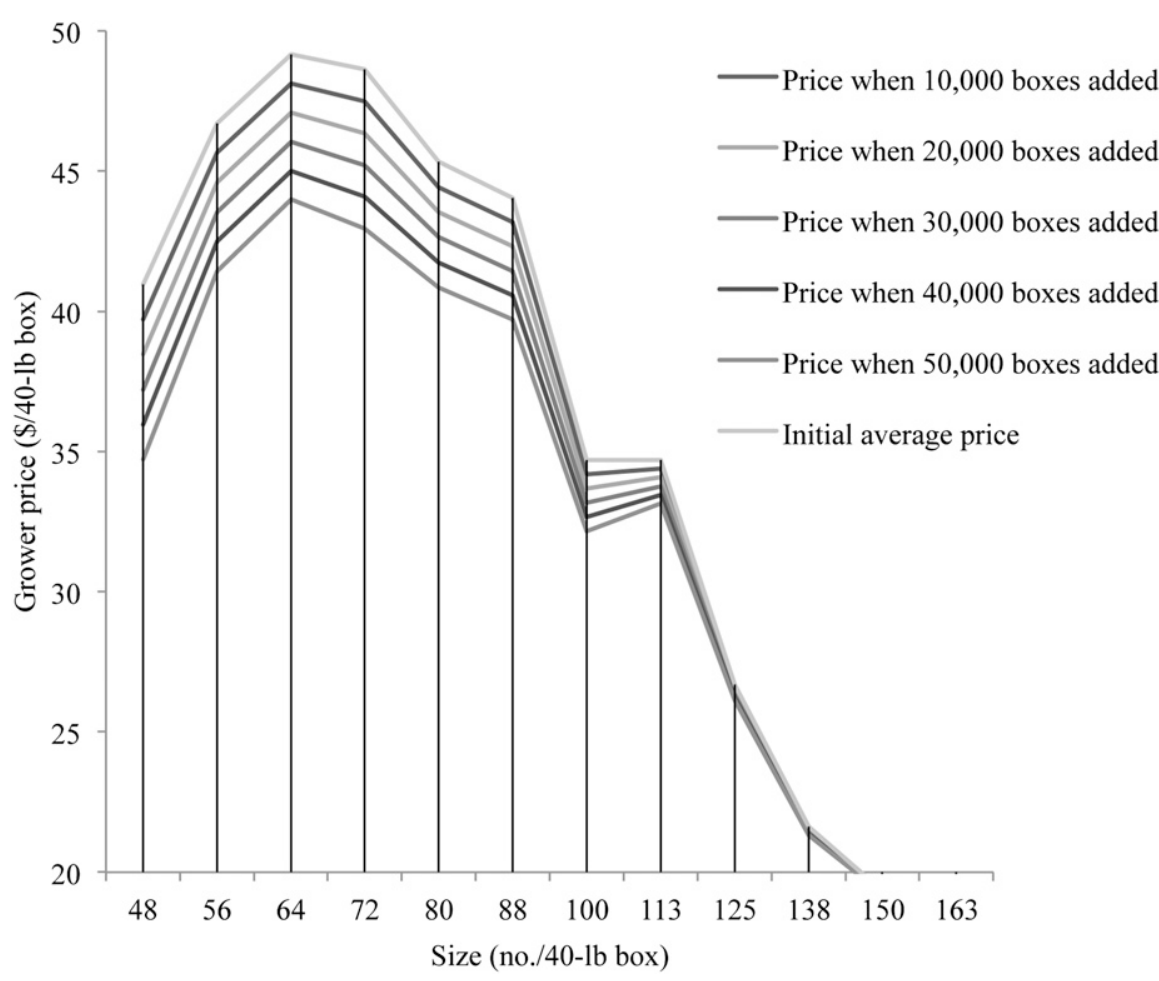

Fig. 2. Variations in 'Honeycrisp' apple estimated grower prices by size category, when quantities shipped of each size category increase; $\$ 1 / 40-1 \mathrm{~b}(18.14 \mathrm{~kg}) \mathrm{box}=\$ 0.0551 / \mathrm{kg}$.

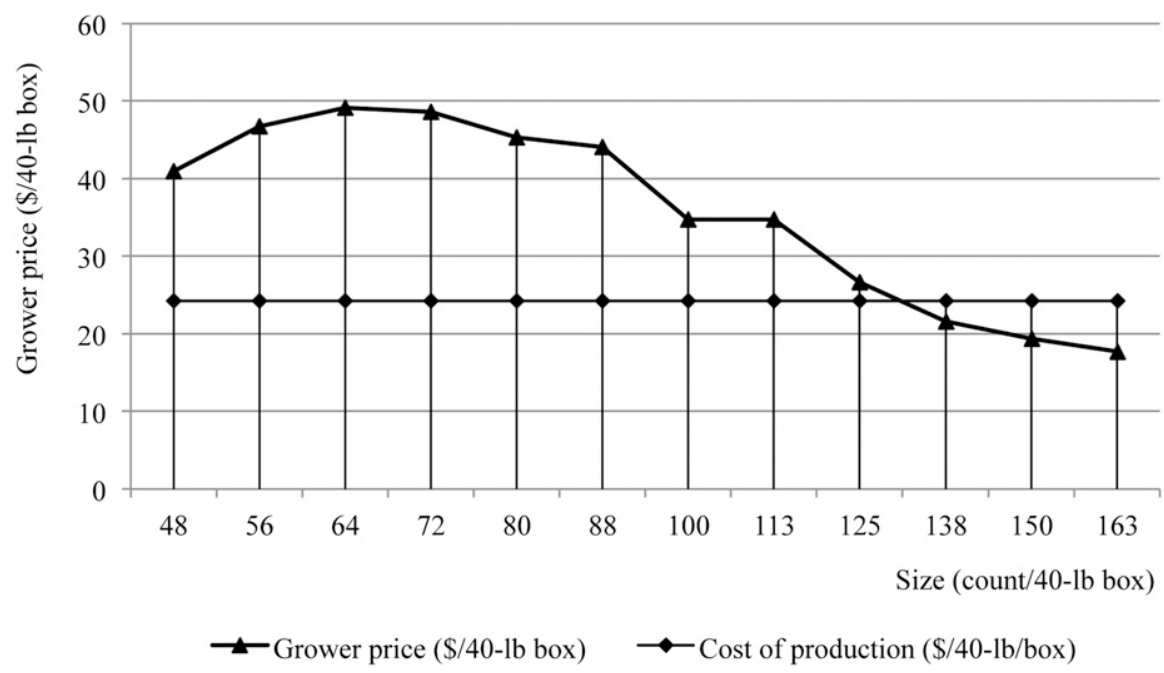

Fig. 3. Estimated 'Honeycrisp' apple grower prices at different sizes vs. the cost of production; $\$ 1 / 40-1 \mathrm{~b}(18.14 \mathrm{~kg})$ box $=\$ 0.0551 / \mathrm{kg}$.

$\$ 0.25 / \mathrm{lb}$ if 'Honeycrisp' apples presented external defects, all other variables constant. SSC and acidity had a quadratic effect on WTP. SSC positively impacted WTP at a decreasing rate. The optimal value for SSC was estimated at $13.8 \%$, all other variables constant. This value was estimated by solving the first derivate of WTP $=1.38$ SSC $-0.05 S S C^{2}$ and equaling it to zero. The inflection point for acidity was calculated in a similar way. unpublished data) in the expression $\mathrm{WTP}=1.38$ SSC $-0.05 \mathrm{SSC}^{2}$ one obtains a distribution of WTP (dollars per pound) for each SSC value and number of fruit per TCA (Fig. 4). The average WTP, of such distribution, is $\$ 0.12 / \mathrm{lb}$, meaning that apple consumers participating in the experimental auction were willing to pay an average of $\$ 0.12 / \mathrm{lb}$ more for a one-unit increase in SSC percentage. This means that participants were expected to discount, on average, $\$ 0.12 / \mathrm{lb}$ for a one-unit decrease in SSC, all other variables constant. Because the relationship between WTP and SSC is quadratic, the discount for lower SSC $(11.6 \%)$ was larger $(\$ 0.23 / \mathrm{lb})$ than the discount $(\$ 0.02 / \mathrm{lb})$ for higher SSC $(13.7 \%)$. If one considers the farm share percentage of fresh apple retail prices, 32\% (USDA, 2015), then the discount for lower SSC farmers face is at $\$ 0.04 / \mathrm{lb}$. This price equals to $\$ 1.54$ per 40 -lb box, or $\$ 31.68$ per $825-1 b$ bin. If one uses the calculator of net returns per acre at various prices and yields of 'Honeycrisp' by Galinato and Gallardo (2012), decreasing the price from $\$ 650$ to $\$ 618$ per $825-1 b$ bin (or a $5 \%$ decrease), lead to a $\$ 1362 /$ acre loss. There is some divergence on the specific range of fruit per square centimeter TCA leading to optimal SSC in 'Honeycrisp'. Although Robinson et al. (2009) signaled that under New York state growing conditions crop loads of five to six fruit $/ \mathrm{cm}^{2}$ TCAyielded fruit with acceptable levels of soluble solids, field trials in eastern Washington as reported by Hanrahan (I. Hanrahan, unpublished data) do not show conclusive evidence of a specific crop load range leading to optimal SSC. Regional growing conditions, like for example light environment, affect the physiology of the tree, explaining partially the divergent results in New York and Washington state (I. Hanrahan, personal communication). Thus, we conclude that to not negatively affect SSC in 'Honeycrisp', fruit loads should be kept under seven fruit $/ \mathrm{cm}^{2}$ TCA. Figure 4 illustrates the relationship among the number of fruit per square centimeter TCA, SSC, and estimated discounts in dollars per pound for decreases in SSC.

\section{Conclusions and implication}

'Honeycrisp' is a cultivar with exceptional eating-quality characteristics 
Table 5. Estimated profits per acre for 'Honeycrisp' apples at various weighted average grower prices.

\begin{tabular}{lccc}
\hline $\begin{array}{l}\text { Change in size } \\
\text { distribution }(\%)^{\mathbf{z}}\end{array}$ & $\begin{array}{c}\text { Weighted avg } \\
\text { price }(\$ / \text { bin })^{\mathbf{y}}\end{array}$ & $\begin{array}{c}\text { Estimated } \\
\text { profit }(\$ / \text { acre })^{\mathbf{y}}\end{array}$ & $\begin{array}{c}\text { Profit } \\
\text { differential }(\$ / \text { acre })\end{array}$ \\
\hline 0 & 878 & 16,268 & 5,332 \\
5 & 754 & 10,936 & 2,150 \\
7 & 704 & 8,786 & 3,182 \\
10 & 630 & 5,604 & 2,150 \\
12 & 580 & 3,454 & 3,182 \\
15 & 506 & 272 & 3,182 \\
18 & 432 & $(2,910)$ & 2,150 \\
20 & 382 & $(5,060)$ & \\
\hline
\end{tabular}

${ }^{2}$ Refers to a proportional change in the distribution of sizes: 0 depicts the weighted average price considering the size distribution reported in Table 4; 5 means that the weighted average price was estimated when the percentage of size $48-88$ count per $40-\mathrm{lb}(18.14 \mathrm{~kg})$ box decreased by $5 \%$ and the percentage of size $100-163$ count per $40-\mathrm{lb}$ box increased by $5 \% ; 7$ means that the percentage of size $48-88$ count per $40-1 b$ box decreased by $7 \%$ and the percentage of sizes $100-163$ count per $40-1 b$ box increased by $7 \%$, similarly for all other percentage changes $10, \ldots, 20$.

甲 $\$ 1 / 825-\mathrm{lb}(374.21 \mathrm{~kg})$ bin $=\$ 2.6723 / \mathrm{Mg}, \$ 1 / \mathrm{acre}=\$ 2.4711 / \mathrm{ha}$.

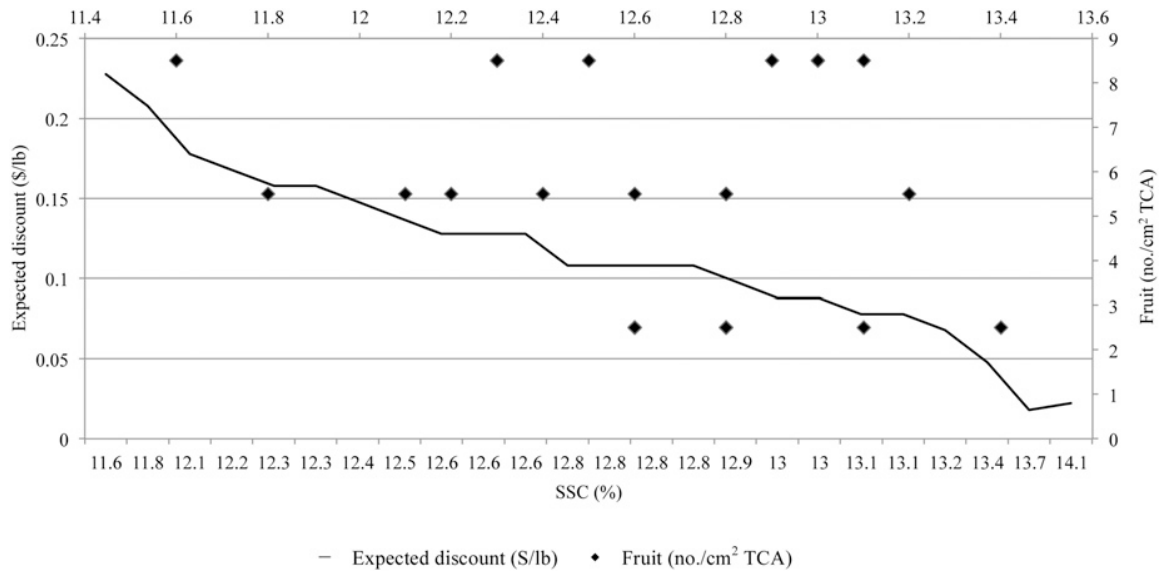

Fig. 4. Relationship across apple consumers' expected discount, soluble solid content (SSC), and number of fruit per unit trunk cross-sectional area (TCA); \$1/ $\mathrm{lb}=\$ 2.2046 / \mathrm{kg}, 1$ fruit $/ \mathrm{cm}^{2} \mathrm{TCA}=6.4516 \mathrm{fruit} / \mathrm{inch}^{2} \mathrm{TCA}$.

that are reflected in its market price premiums compared with other popular apple cultivars in the United States. However, 'Honeycrisp' is susceptible to disorders if not managed adequately during the pre- and postharvest periods. Given the myriad of factors that could potentially impact 'Honeycrisp' quality, we focus on two specific consequences of inadequate crop load management: fruit size and SSC. This study estimated the potential impact on grower profits when the number of fruit per tree was not optimal using two different methodologies. First, we used a hedonic pricing model to estimate the effect of 'Honeycrisp' fruit sizes on prices received by growers. We linked results from previous studies on the effects of number of fruit per trunk area on fruit size with the potential profits to be obtained from producing different 'Honeycrisp' sizes. Second, we used experimental auctions to estimate consumers' WTP for 'Honeycrisp' quality characteristics (e.g., size, absence of defects, firmness, SSC, and tartness). We linked WTP results with previous studies on the effects of number of fruit per square centimeter TCA on SSC to estimate potential losses when not supplying 'Honeycrisp' with optimal SSC levels.

All other variables constant, fruit sizes of 64 to 72 count per 40 -lb box exhibit the highest predicted grower prices ( $\$ 49.2$ to $\$ 48.6$ per box). A grower would realize a loss of $\$ 5332$ /acre if production of size 48 to 88 count/box decreased by $5 \%$ and size 100 to 163 count/box increased by $5 \%$ compared with current 'Honeycrisp' size distribution. We also found that apple consumers participating in an experimental auction were willing to pay an average of $\$ 0.12 / \mathrm{lb}$ more for a one-unit increase in SSC. A $\$ 0.12 / \mathrm{lb}$ discount for a decrease in SSC would represent a \$1362/acre loss. Optimal sizes and SSC estimated in this study are linked with crop loads no larger than seven fruit $/ \mathrm{cm}^{2}$ TCA, under Washington state growing conditions.

This study illustrates potential profit losses if 'Honeycrisp' apples are not supplied with exceptional characteristics in terms of fruit size and SSC. Given the increasing popularity of 'Honeycrisp', growers and allied industries should be aware of the importance of preserving the quality of this cultivar to maintain price premiums and thus profit margins. If low-quality fruit is supplied to the market, consumers will eventually notice and preferences may switch to alternative cultivars, fruit, or foods.

\section{Literature cited}

Colson, G.J., W.E. Huffman, and M.C. Rousu. 2011. Improving the nutrient content of food through genetic modification: Evidence from experimental auctions on consumer acceptance. J. Agr. Resource Econ. 36:343-364.

Corrigan, J.R. and M.C. Rousu. 2008. Testing whether field auction experiments are demand revealing in practice. J. Agr. Resource Econ. 33:290-301.

De Castro, E., W.V. Biasi, and E.J. Mitcham. 2007. Quality of pink lady apples in relation to maturity at harvest, pre-storage treatments, and controlled atmosphere during storage. HortScience 42:605-610.

Daillant-Spinnler, B., H.J.H. MacFie, P.K. Beyts, and D. Hedderley. 1996. Relationships between perceived sensory properties and major preference directions of 12 varieties of apples from the southern hemisphere. Food Qual. Prefer. 7:113-126.

DeEll, J. and B. Ehsani-Moghaddam. 2010. Preharvest 1-mthylcyclopropene treatment reduces soft scald in 'Honeycrisp' apples during storage. HortScience 45:414-417.

Dinis, I., O. Simoes, and J. Moreira. 2011. Using sensory experiments to determine consumers' willingness to pay for traditional apple varieties. Span. J. Agr. Res. 9:351-362.

Embree, C.G., M.T.D. Myra, D.S. Nichols, and A.H. Wright. 2007. Effect of blossom 
density and crop load on growth, fruit quality, and return bloom in 'Honeycrisp' apple. HortScience 42:1622-1625.

Fallahi, E., B. Fallahi, G.H. Neilsen, D. Neilsen, and F.J. Peryea. 2008. Effects of mineral nutrition on fruit quality and nutritional disorders in apples. Acta Hort. 868:49-60.

Feuz, D., W.J. Umberger, C.R. Calkins, and B. Sitz. 2004. U.S. consumers' willingness to pay for flavor and tenderness in steaks as determined with an experimental auction. J. Agr. Resource Econ. 29:501516.

Galinato, S. and R.K. Gallardo. 2012. 2011 Cost estimates of establishing, producing, and packing 'Honeycrisp' apples in Washington. Washington State Univ. Ext. Factsheet FS062E.

Good Fruit Grower. 2014. Tips to storing 'Honeycrisp'. 9 Mar. 2015. <http:// www.goodfruit.com/tips-for-storinghoneycrisp $/>$.

Schotzko, R.T., R.C. Mittelhammer, and P. Gutman. 2001. Effect of size and grade on profitability of marketing D'Anjou pears. Pacific Northwest Pear Bureau, Portland, OR

Huang, S. 2013. Imports contribute to year-round fresh fruit availability. U.S. Dept. Agr. Econ. Res. Serv. FTS 356-01. 11 Mar. 2015. <http://www.ers.usda. gov/publications /fts-fruit-and-treenuts-outlook/fts-356-01.aspx>.

Huffman, W.E., J.F. Shogren, M. Rousu, and A. Tegene. 2003. Consumer willingness to pay for genetically modified food labels in a market with diverse information: Evidence from experimental auctions. J. Agr. Resource Econ. 28:481501 .

Jesionkowska, K., D. Konopacka, and W. Plocharski. 2006. The quality of apples: Preferences among consumers from Skierniewice, Poland. J. Fruit Ornamental Plant Res. 14:173-182.

Kajikawa, C. 1998. Quality level and price in Japanese apple market. Agribusiness $14: 227-234$

Lee, J.Y., D.B. Han, R.M. Nayga, and S. Lim. 2011. Valuing traceability of imported beef in Korea: An experimental auction approach. Austral. J. Agr. Resour. Econ. 55:360-373

Luby, J.J. and D.S. Bedford. 1992. 'Honeycrisp' apple. Univ. Minnesota, Agr. Expt. Sta. Rpt. 225-1992 (AD-MR5877-B)

Lusk, J.L. and J.F. Shogren. 2007. Experimental auctions methods and applications in marketing research. Cambridge Univ. Press, Cambridge, UK.
Manalo, A.B. 1990. Assessing the importance of apple attributes: An agricul tural application of conjoint analysis. Northern J. Agr. Resource Econ. 19:118124.

Marin, A.B., A.E. Colonna, K. Kudo, E.M. Kupferman, and J.P. Mattheis. 2009. Measuring consumer response to 'Gala' apples treated with 1-methylcyclopropene (1-MCP). Postharvest Biol. Technol. 51: 73-79.

McCluskey, J.J., R.C. Mittelhammer, A.B. Marin, and K.S. Wright. 2007. Effect of quality characteristics on consumers' willingness to pay for 'Gala' apples. Can. J. Agr. Econ. 55:217-231.

McCluskey, J.J., B.P. Horn, C.A. Durham, R.C. Mittelhammer, and Y. Hu. 2013. Valuation of internal quality characteristics across apple cultivars. Agribusiness 29:228241.

Miller, S.S., R.W. McNew, B.H. Barritt, L. Berkett, S.K. Brown, J.A. Cline, J.M Clements, W.P. Cowgill, R.M. Crassweller, M.E. Garcia, D.W. Greene, G.M. Greene, C.R. Hampson, I. Merwin, D.D. Miller, R. E. Moran, C.R. Rom, T.R. Roper, J.R. Schupp, and E. Stover. 2005. Effect of cultivar and site on fruit quality as demonstrated by the NE-183 regional project on apple cultivars. HortTechnology $15: 886-895$

Nalley, L.L., D. Hudson, and G. Parkhurst. 2006. Consistency of consumer valuation under different information sets: An experimental auction with sweet potatoes. J. Food Distribution Res. 37:5767.

Plattner, K., A. Perez, and S. Thornsbury. 2014. Seasonal fresh fruit price patterns differ across commodities: The case of strawberries and apples. 23 Feb. 2015. <http://www.ers. usda.gov/amber-waves/2014-october/ seasonal-fresh-fruit-price-patternsdiffer-across-commodities-the-case-ofstrawberries-and-apples . asp $\mathrm{x} \#$. VOtkuSlh0fA>.

ProChile. 2011. Marketing study for pome fruit: Pears and apples in Mexico. 4 May 2015. <http://www.prochile.gob. cl/wp-content/blogs.dir/1/files_mf/ documento_05_03_11155618.pdf $>$.

Quagraine, K.K. and J.J. McCluskey. 2003. A latent structure approach to measuring reputation. South. Econ. J. 69:966-977.

Robinson, T., S. Lopez, K. Iungerman, and G. Reginato. 2009. Crop load management for consistent production of 'Honeycrisp' apples. New York Fruit Qrtly. 17(1):24-28.

Robinson, T.L. and C.B. Watkins. 2003 Crop load of 'Honeycrisp' affects not only fruit size but also many quality attributes. New York Fruit Qrtly. 11(3):7-10.

Robinson, T.L. 2008. Crop load management of new high-density apple orchards. New York Fruit Qrtly 16(2): $3-7$.

Schupp, J., R. Straub, D. Rosenberger, and C. Watkins. 2001. Managing 'Honeycrisp' for production and quality. Compact Fruit Tree 34(4):107-109.

Tustin, D.S., P.M. Hirst, and I.J. Warrington. 1988. Influence of orientation and position of fruiting laterals on canopy light penetration, yield, and fruit quality of 'Granny Smith' apples. J. Amer. Soc. Hort. Sci. 113:693-699.

U.S. Apple Association. 2014. Production and utilization analysis for the 2014 U.S. 8 May 2014. <https:// ciderconferencedotcom.files.wordpress. com / $2015 / 01 / 2014$ - us a p ple production-utilization-analysis.pdf $>$.

U.S. Department of Agriculture. 2002. United States Standards for Grades and Apples. 24 Feb. 2015. <http://www. google.com $/$ url? $s a=t \& r c t=j \& q=\& e s r c=s \&$ source $=$ web \&cd $=1 \&$ ved $=0 \mathrm{CB} 4 \mathrm{QFjAA} \&$ url=http $\% 3 \mathrm{~A} \% 2 \mathrm{~F} \% 2 \mathrm{Fwww}$.ams.usda.gov>.

U.S. Department of Agriculture. 2011. Tree fruit acreage report. 5 May 2015. <http://www.nass.usda.gov/Statistics_ by_State/Washington/Publications / Fruit/>

U.S. Department of Agriculture. 2014. U.S. apple statistics. 24 Feb. 2015. <http://usda.mannlib.cornell.edu/ MannUsda/viewDocumentInfo.do? documentID $=1825>$.

U.S. Department of Agriculture. 2015. Price spreads from farm to consumer. 8 May 2014. <http://www.ers.usda.gov/ data-products/price-spreads-from-farmto-consumer.aspx $>$.

U.S. Department of Commerce. 1990. United States Patent Plant 7,197. 5 May 2015 . < h t t p: / / w e b c a che. googleusercontent.com/search?q=cache: 4ki5HQbjr4UJ:patentimages.storage. googleapis.com/pdfs/USPP7 197. $\mathrm{pdf}+\& \mathrm{~cd}=1 \& \mathrm{hl}=\mathrm{en} \& \mathrm{ct}=\mathrm{clnk} \& \mathrm{gl}=\mathrm{us}>$.

Volinsky, D., W.L. Adamowicz, M. Veeman, and L. Srivastava. 2009. Does choice context affect the results from incentive-compatible experiments? The case of non-GMO and country-of-origin premia in canola oil. Can. J. Agr. Econ. 57:205-221.

Wargo, J.M. and C.B. Watkins. 2004. Maturity and storage quality of 'Honeycrisp' apples. HortTechnology 14:496499.

Washington Growers Clearing House Association. 2013. Apple summary re- 


\section{Production and Marketing Reports}

ports. 24 Feb. 2015. <http://www. waclearinghouse.org $/>$.

Watkins, C.B. and J.F. Nock. 2011. Towards controlled atmosphere storage for 'Honeycrisp' apples. New York Fruit Qrtly. 19(4):7-11.

Watkins, C.B. and J.F. Nock. 2012. Controlled atmosphere storage of 'Honeycrisp' apples. HortScience 47:886-892.

Watkins, C.B., M. Erkan, J.F. Nock, K.A. Iungerman, R.M. Beaudry, and R.E. Moran. 2005. Harvest date effects on maturity, quality, and storage disorders of 'Honeycrisp' apples. HortScience 40: 164-169.

Wayua, F.O., M.G. Shibia, M.S. Mamo, D. Bailey, and D.L. Coppock. 2009.
Willingness to pay for improved milk sensory characteristics and assurances in northern Kenya using experimental auctions. Intl. Food Agribusiness. Mgt. Rev. 12:69-88.

Winfree, J.A. and J.J. McCluskey. 2005. Collective reputation and quality. Amer. J. Agr. Econ. 87(1):206-213.

Wright, A.H., C.G. Embree, D.S. Nichols, R.K. Prange, P.A. Harrison, and J.M. DeLong. 2006. Fruit mass, colour and yield of 'Honeycrisp' apples are influenced by manually adjusted fruit population and tree form. J. Hort. Sci. Biotechnol. 81:397-401.

Yue, C. and C. Tong. 2009. Organic or local? Investigating consumer preference for fresh produce using a choice experi- ment with real economic incentives. HortScience 44:366-371.

Yue, C., C. Hall, B.K. Behe, B.L. Campbell, J.H. Dennis, and R.G. Lopez. 2010. Are consumers willing to pay more for biodegradable containers than for plastic ones? Evidence from hypothetical conjoint analysis and nonhypothetical experimental auctions. J. Agr. Appl. Econ. 42:757-772.

Yue, C., T. Hurley, and N.O. Anderson. 2012. Heterogeneous consumer preferences for native and invasive plants: Evidence from experimental auctions. HortScience 47:1091-1095. 